Original Research Article

\title{
School absenteeism effects on scholastic performance- reality check in India
}

\author{
Harisha Gopal ${ }^{1}$, Bhaskar S. ${ }^{2}$ \\ ${ }^{1}$ Dr. Harisha Gopal, Assistant Professor, ${ }^{2}$ Dr. Sandeep Bhaskar, Assistant Professor, both authors are affiliated \\ with Vydehi Institute of Medical Sciences, Whitefield, Bangalore, Karnataka, India \\ Address for Correspondence: Dr Sandeep Bhaskar, Assistant Professor, Vydehi Institute of Medical Sciences, \\ Whitefield, Bangalore. E-mail: Sandeepthelion27@gmail.com
}

\begin{abstract}
Introduction: School absenteeism is an important issue, which affects educational achievement and also results in false estimation of the prevalence of disease in school programs. This study was carried out to estimate the magnitude and its causes and its relation to school absenteeism. Objectives: 1 . To study the medical causes \& social factors affecting school absenteeism. 2. To know the effect of school absenteeism on scholastic performance. Method: It is a cross sectional study done in randomly selected in the age five to fifteen years. The study sample included 754 children. Socio-demographic profile and pre-designed questionnaires as well as school records were obtained. The marks cards of the entire year where taken to assess the scholastic performance. Significant absenteeism was taken when absenteeism was more than 15 percent. Results: The incidence of school absenteeism was 3.1 percent .Increased incidence was found in children aged 11 to 14 years. There is increased incidence of absenteeism seen in male with the increase in the birth order and family size, with low education status of the parents and in Hindu religion. Majority of the school children were anemic. Illness is the most important cause of school absenteeism. Poor academic performance is significantly associated with incidence of absenteeism. Conclusion: Illness constituted the major reason of absenteeism. School absenteeism had positive correlation with the academic performance of the students.
\end{abstract}

Key words: Absenteeism, Academic performance, School children

\section{Introduction}

School, colleges and universities have no worth without student. Students are most essential asset for any educational institute. The social and economic development of the country is directly linked with student academic performance. The students' performance (academic achievement) plays an important role in producing the best quality graduates who will become great leader and manpower for the country thus responsible for the country's economic and social development. Student academic performance measurement has received considerable attention in previous research, it is challenging aspects of academic literature, and science student performance are affected due to social, psychological, economic,

Manuscript received: $07^{\text {th }}$ June 2017

Reviewed: $14^{\text {th }}$ June 2017

Author Corrected: $20^{\text {th }}$ June 2017

Accepted for Publication: $30^{\text {th }}$ June 2017 environmental and personal factors. These factors strongly influence on the student performance, but these factors vary from person to person and country to country [1].

School absenteeism has been linked to maternal education, residence, and specific illnesses like asthma, headache, abdominal pain, etc. [2-6] but other causes and relation to academic performance has not been evaluated. School absenteeism is an important issue, which affects not only educational achievement but also results in false estimation of the prevalence of disease in school based screening programs. Further, school based intervention programs may miss out several affected children [7]. This study was, therefore, carried out to estimate the magnitude of school absenteeism and identify its causes. 
Original Research Article

\section{Methods}

Study design: :School absenteeism conceptual models were structured to in order to measure the phenomenon associated with problematic school absenteeism, namely, school-related absenteeism and parental condoned absenteeism.

School-Related Absenteeism Conceptual Model: The Student Questionnaire: School-Related Absenteeism incorporates a questionnaire in order to assess students' perceptions of specific situations relevant to problematic school absenteeism. The rationale for employing this particular questionnaire highlights categories and risk factors associated with problematic school absenteeism.

Parental Condoned Absenteeism Conceptual Model: The School Questionnaire: Parental Condoned absenteeism model incorporates questionnaire in order to assess schools' measurement of parental condoned absenteeism. The rationale for employing this particular questionnaire is to elicit specific information relevant to parental condoned absenteeism [8].

The present study is a prospective study conducted in rural school, for a period of one year June 2014 to May 2015 was taken. A total of 754 students who fulfilled the inclusion criteria were included in the study. Clearance was obtained from the ethical committee.

Inclusion criteria: School children aged between five to 15 years who were absent for more than $15 \%$.

Exclusion criteria: 1) School children below five and above 15 years. 2) Children who were absent for less than $15 \%$

Method of collection of data: The objectives of the study were explained and informed consent was obtained from the school head, parents and teachers to participate in the study. Total of 754 children, of both sexes in the age group five to 15 years were taken in different standards. Each standard had three to five sections. One section per standard was randomly selected and all students in selected classes were eligible for enroll. Where there were more than three sections per standard, two were chosen randomly. Informed written consent was taken from the participants included in the study.

At enrolment, information on socio-demographic profile of the students was collected. It included age, sex, class, education and occupation of the parents, their family structure and income. A pre-designed questionnaire as mentioned above was administered to ascertain the duration of absence and the causes for absenteeism, medical and non-medical. Participants were assured of confidentiality and were enquired about school truancy and various phobias of schools, teachers and subjects. The causes of absenteeism were also ascertained by school records, leave applications and one month's recall by the students. Students, teachers and parents were interviewed whenever needed.

Detailed data was obtained from those students who were absented for the whole day for more than 15 percent of the total days. The marks cards of the test and exams performed in the entire year will be taken to assess the scholastic performance. A total of 754 students were registered. The total number of working days was 240 days over the last 12 months. Significant absenteeism was taken when absenteeism was more than 15\% [9].

Statistical Methods: Descriptive statistical analysis has been carried out in the present study. Results on continuous measurements are presented on Mean \pm SD (Min-Max) and results on categorical measurements are presented in Number (\%). Significance is assessed at $5 \%$ level of significance. Chi-square/ Fisher Exact test has been used to find the significance of study parameters on categorical scale between two or more groups.

\section{Chi-Square Test}

$$
\chi^{2}=\frac{\sum\left(O i-E_{i}\right)^{2}}{E_{i}}, \text { Where Oi is observed frequency and Ei is Expected frequency }
$$




\section{Fisher Exact Test}

\begin{tabular}{|c|c|c|c|}
\hline & Class 1 & Class 2 & Total \\
\hline Sample1 & A & $\mathrm{b}+\mathrm{b}$ \\
\hline Sample2 & C & $\mathrm{d}$ & $\mathrm{c}+\mathrm{d}$ \\
\hline Total & $\mathbf{a}+\mathbf{c}$ & $\mathbf{b}+\mathbf{d}$ & $\mathbf{n}$ \\
\hline
\end{tabular}

$2 \times 2$. Fisher Exact Test statistic $=$

$$
\sum p=\frac{(a+b) !(c+d) !(a+c) !(b+d) !}{n !} \frac{1}{\sum a ! b ! c ! d !}
$$

\section{Significant figures}

+ Suggestive significance ( $\mathrm{P}$ value: $0.05<\mathrm{P}<0.10$ )

* Moderately significant ( $\mathrm{P}$ value:0.01<P $£ 0.05$ )

** Strongly significant (P value: $\mathrm{P} £ 0.01)$

Statistical software: The Statistical software namely SAS 9.2, SPSS 15.0, Stata 10.1, MedCalc 9.0.1, Systat 12.0 and R environment ver.2.11.1 were used for the analysis of the data and Microsoft word and Excel have been used to generate graphs, tables etc.

\section{Results}

Students were randomly selected from Class one to class ten in the study.

\section{Table-1}

\begin{tabular}{|c|c|c|}
\hline Cause of School absenteeism & Number of Children & \% \\
\hline 1.Illness & (n=23) & 43.47 \\
\hline 2.Family problems & 2 & 8.7 \\
\hline 3.School load & 2 & 8.7 \\
\hline 4.School Phobia & 2 & 8.7 \\
\hline 5.School truancy & 2 & 4.3 \\
\hline 6.Chronic Illness & 1 & 4.3 \\
\hline 7.Family Function & 1 & 4.3 \\
\hline 8.Family Illness & 1 & 4.3 \\
\hline 9.Perception of Ill health & 1 & 4.3 \\
\hline 10.Tuitions & 1 & \\
\hline
\end{tabular}


Female students were more compared to male students in the study. The incidence of school absenteeism was 3.1 percent ( 23 children) in our study. Increased incidence was found in children aged 11 to 14 years (early adolescent group) due to unique problems faced by adolescent group. There was increased incidence of absenteeism in male gender compared to females.

There was increased absenteeism in second to third order of birth as parents were finding it difficult to take care of all the children at the same time effectively. Students from Hindu religion are more absent than non-Hindus as they have many festivals and functions. There was increased incidence of absenteeism when Mother's education is low as mother is first and best teacher in home. Mothers are significant predictors of incidence of absenteeism.

Students coming from surrounding areas of the school had increased incidence of absenteeism because of transportation problems. There was increased school absenteeism when family size increased above four as children as individual attention could not be given to all the children. Students whose parents are working in shop or as a clerk found to be more absent than others.

Majority of the school children had anemia followed by respiratory problems. Complaints were present in $(5.91 \%)$ of the children of which majority had pallor (anemia) followed by cough. Illness was the the most important cause of school absenteeism.

Table-2

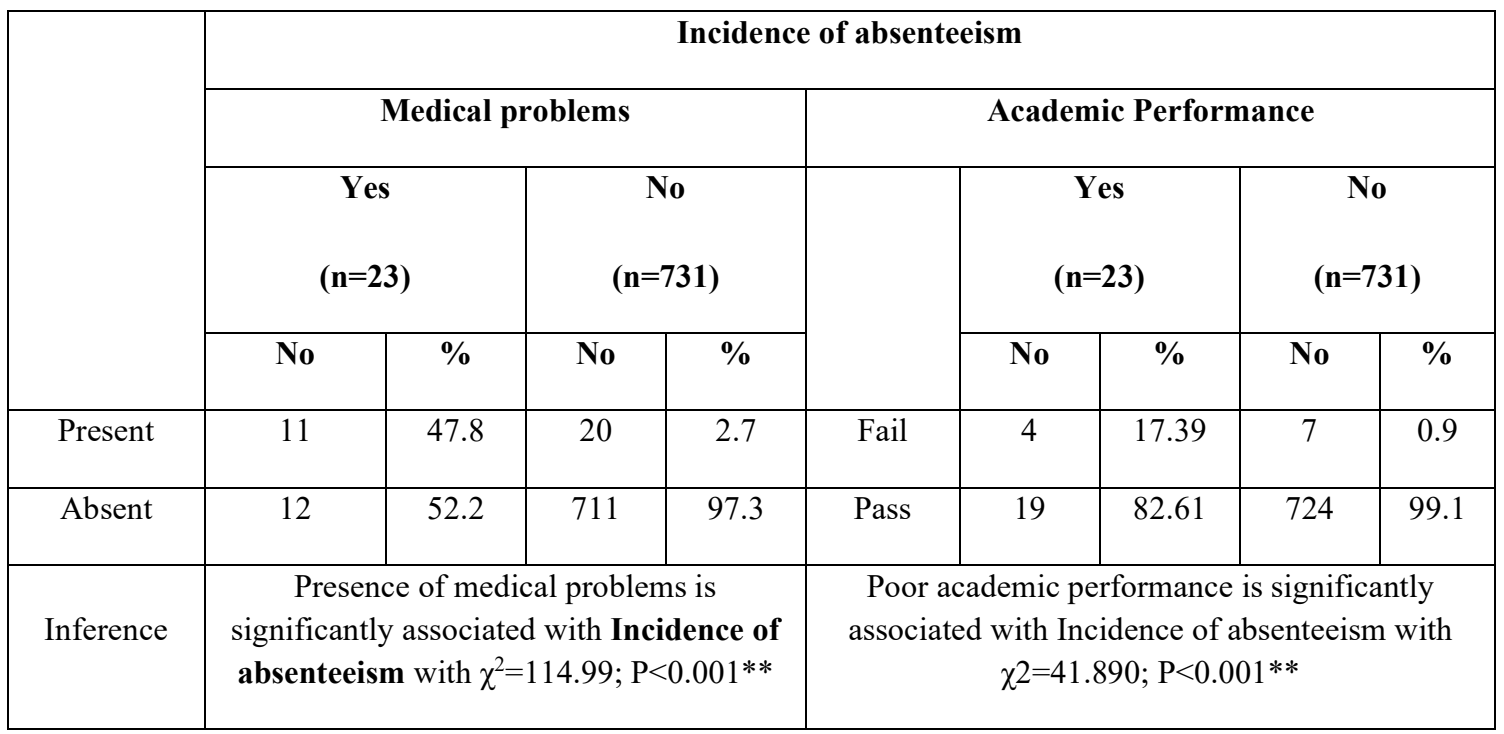

Presence of medical problems is significantly associated with incidence of absenteeism. Poor academic performance is significantly associated with Incidence of absenteeism.

\section{Discussion}

An extensive review of literature on problematic school-related absenteeism identifies it as a worldwide phenomenon of immense and increasing proportion and has categorized PSRA into five broad areas: truancy; school refusal; delinquency; early school withdrawal; and parental condoned absenteeism.

Truancy : is only one of several terms associated with PSRA, but is perceived to be the main category and attracts most of the attention in research into this phenomenon [10-12] . Truancy is defined as unjustifiable or unexplained absence from school with attempts by the student to conceal the absenteeism. Usually the child avoids home when not at school and the parents are often unaware of the child's absence [13-14].

There are two types of truancy: chronic and occasional. Chronic truants are students who are 
absent without approval for $20 \%$ or more of school time [15].

School Refusal: School refusal refers to absence by children who refuse to attend school in the face of persuasion and punishment by parents, and of possible school discipline. This form of absenteeism is widely recognized as a disorder involving persistent non-attendance at school, excessive anxiety and physical complaints. Two contributing factors include avoidance behavior in relation to school, and active seeking of situations that provide comfort and security [16].

Delinquency: Delinquency refers to the committing of a minor crime or non-serious misconduct by a juvenile.

Early School Withdrawal: Early school withdrawal refers to absence by children whose parents keep them away from school on a regular or long-term basis, for reasons related to the needs of the family, or children who have chosen not to attend school for their own reasons [8].

Parental Condoned Absenteeism: Parental condoned absenteeism refers to parental approved withdrawals such as family functions, holidays, and personal appointments. Directly or indirectly, parents play a major role in keeping their children absent from school. Parents held that schools were responsible for students' attendance at school whilst schools held that parents were responsible [8].

Incidence: The Incidence of school absenteeism was 3.1 percent of which males constituted $(60.91 \%)$ \& females constituted $(39.09 \%)$. A wide range of incidence of school absenteeism has been recorded in different studies ranging from $(4.73 \%)$ to $(17.84 \%)$ [17]. This diversity of incidence of absenteeism is mainly due to varying groups taken for the study and basic differences between rural subgroups related to geographic ,educational status ,cultural factors and religion. Similar incidence of School absenteeism has been observed by other authors [18].

Sex: Present study shows that incidence of absenteeism is higher in males (60.91\%) compared to females $(39.09 \%)$ which is similar to studies done by Awasthi et al [18] and Sreenivas et all [19]. However Ananthakrishan et al [20] found no significant gender difference. The differences may be attributable to different settings of the study.
Family Influence: Present study shows that parent education especially mother's education are significant predictors of incidence of absenteeism, which is similar to study done by other studies $[9,18,20,21]$. Present study shows that incidence of absenteeism is less in smaller families less than four $(21.76 \%)$ compared to family size greater than four $(78.71 \%)$ similar to the study done by Sreenivas et all [19].

Illness: The present study shows that illness is the major cause of school absenteeism (43.47\%) which is similar to study done by Sreenivas et all [19].

Effect on scholastic performance: Present study shows that more students failed among absentees $(17.39 \%)$ when compared to non-absentees $(0.95 \%)$ which is similar to study done by Romero et all [22].

Hence illness constituted the major reason for school absenteeism and school absenteeism had positive correlation with the academic performance of the students.

\section{Conclusions}

Male sex, increasing birth border and family size, lower parental education and income were identified to be associated with significant school absenteeism.

- Gender, age group ,birth order, parents education and income, illness, school phobia, school truancy, school load and getting absent for family reasons were found to be independent significant factors responsible for school absenteeism.

- Of the above illness constituted the major reason for school absenteeism.

- School absenteeism had positive correlation with the academic performance of the students.

Contributions: HG conceptualized and designed the study, interpreted data, revised manuscript and approved the final version to be published. He will act as guarantor of the study. HG acquired the data, drafted the article and helped in final approval of the manuscript. SB analyzed the data, revised contents and helped in final approval.

\section{What is already known?}


- School absenteeism is associated with asthma, headache, abdominal pain, , younger age, increasing birth order and lower parental education and income.

\section{What this study adds?}

- This study provides a model to predict absenteeism in school children based on its correlates and also identifies illness as a major cause with anemia as a common problem as new independent significant factors associated with school absenteeism, which is more in adolescent age group especially males and also shows that poor academic performance is significantly associated with increase in the incidence of absenteeism

Funding: Nil, Conflict of interest: None initiated, Perission from IRB: Yes

\section{References}

1. Ali N, Jusoff K, Ali S, et all.The Factors Influencing Students' Performance at Universiti Teknologi MARA Kedah, Malaysia. Management science and Engineering. 2009;3(4): 81-90.

2. Parcel GS, Gilman SC, Nader PR, Harvey B. A comparison of absentee rates of elementary school children with asthma and non asthmatic schoolmates. Pediatrics 1979; 64: 878-881.

3. Millard MW, Johnson PT, Hilton A, Hart M. Children with asthma miss more school: fact or fiction? Chest. 2009 Feb;135(2):303-306. doi: 10.1378/chest.08-1642. Epub 2008 Oct 10.

4. Breuner CC, Smith MS, Womack WM. Factors related to school absenteeism in adolescents with recurrent headache. Headache 2004; 44: 217-222.

5. Unalp A. Prevalence and characteristics of recurrent headaches in Turkish adolescents. Pediatric Neurology 2006; 34: 110-115

6. Saps M, Seshadri R, Sztainberg M, Schaffer G,Marshall BM, Di Lorenzo C. A prospective school based study of abdominal pain and other common somatic complaints in children. Journal of Pediatrics 2009;154: 322-326.
7. Ananthakrishnan S, Nalini P. School absenteeism in a rural area in Tamil Nadu. Indian Pediatr 2002;39: 847-850.

8. Robert WR. The Phenomenon of problematic school absenteeism [PhD thesis].Faulty of education:Australian Catholic University;2004.

9. Reid K. The self- concept and persistent school absenteeism.Br J Educ Psychol 1982; 52: 179-187.

10. Atkinson, M, Halsey K, Wilkin A, Kinder K. Raising Attendance, Working Practices and Current Initiatives within the Education Welfare Service. National Foundation for Educational Research; 2002 Oct. Report No.2000a.

11. Brown D. Truants, Families and Schools: A Critique of the Literature on Truancy.Educational Review.1983;35:225-235.

12. Malcolm H, Wilson V, DavidsonJ, Kirk S.Absence from School: A study of its causes and effects in seven LEAs.The SCRE Centre, University of Glasgow;2003. Report No.:RR424.

13. Marilyn C, SilvioB ,Gabriella C,Frans C, Raymond P. Ministry of Education, Youth and Employment School attendance improvement Report.Floriana;2005 Oct.

14. Rollings S., King N, Tonge B, Luk E, Heyne D, RamsdellS, et al. Truancy: Interventions with students, families and school personnel. A Stitch in Time: Issues in Child and Adolescent Mental Health. 1999;3:221-224

15. Andrew JN.Official Hansard: 1999: Proceedings of the $39^{\text {th }}$ Australian Conference of House of Representatives Standing Committee on Employment Education and training, Truancy and Exclusion from School (Canberra);1999 Sep.Report No. 9581-9603.

16. Fisher H. Anglicare Werribee Family Services. Primary School Attendance Intervention.Social Policy Research Centre,University of New South Wales; 2000 Apr. Report No:2/01.

17. Besculides M, Heffernan R, Mostashari F, Weiss D. Evaluation of school absenteeism data for early outbreak detection, New York City. BMC Public Health 2005; 5: 105. 
18. Awasthi S, Sharma A. Survey of school health and absenteeism in Lucknow. Indian Pediatr. 2004 May;41(5):518.

19. Sreenivas V , Preena U ,Premila P.School Absenteeism Among Children and its Correlates: A Predictive Model for Identifying Absentees. Indian Pediatrics.2009 Oct30;(1):1-5.

20. Ananthakrishnan S, Nalini P. School absenteeism. in a rural area in Tamil Nadu. Indian Pediatr 2002;39: 847-850.
21. Gupta JP. An exploratory study of absenteeism in a school in a suburban area in New Delhi. Indian J Pediatr 1968; 35: 299-313.

22. Romero M , Lee Y.A National Portrait of Chronic Absenteeism in the Early Grades. National Center for Children in Poverty,Mailman School of Public Health, Columbia University;2007 Oct.

\section{How to cite this article?}

Harisha Gopal, Bhaskar S. School absenteeism effects on scholastic performance- reality check in India. J PediatrRes.2017;4(06):422-428.doi:10.17511/ijpr.2017.i06.12. 